\title{
Por um lugar ao sol: a política externa alemã de Otto Von Bismarck a Guilherme II
}

\author{
A Place in the Sun: German Foreign Policy \\ from Otto von Bismarck to Wilhelm II
}

Rev. Bras. Est. Def. v. 7, nº 1, jan./jun. 2020, p. 213-239

DOI: $10.26792 /$ RBED.v7n1.2020.75200

ISSN 2358-3932

\section{DANNY ZAHREDDINE BRUNO PIMENTA STARLING}

\section{INTRODUÇÃO}

Passados cem anos da Conferência de Paz de Paris, e com o objetivo de compreender as transformações do sistema internacional no período que precede a Primeira Guerra Mundial, o presente artigo tem seu foco no rápido desenvolvimento e crescimento da Alemanha, entre os anos de 1871 e 1914, e a ascensão de sua importância nas tomadas de decisão em âmbito internacional.

Outrora um confuso aglomerado de Estados sem muita relevância internacional, a Alemanha, após a unificação concluída em 1871, passa a desempenhar um papel cada vez mais significativo nas relações internacionais. Com as guerras de conquista e a consequente expansão territorial, o surgimento do Império Alemão perturbou o equilíbrio de poder na Europa.

Nesse sentido, as questões que nortearão este artigo serão: (1) como a Alemanha conseguiu se transformar em uma potência de nível mundial, entre os anos de 1871 e 1914, tornando-se um dos principais atores do sistema internacional no período? (2) como podemos entender a percepção que as lideranças alemãs tinham do Sistema Internacional, entre $1871 \mathrm{e}$ 1914, e compreender suas ações baseadas nessa percepção? (3) quais os

\footnotetext{
Danny Zahreddine - Diretor do Instituto de Ciências Sociais da PUC Minas. Professor do Departamento de Relações Internacionais e do Programa de Pós Graduação em Relações Internacionais (Stricto Sensu) da PUC Minas (professor permanente). Bacharel em Relações Internacionais, mestre e doutor em Geografia (Tratamento da Informação Espacial) pela PUC Minas.

Bruno Pimenta Starling - Bacharel em História pela Universidade Federal de Minas Gerais - UFMG (2007), Especialista em Estudos Diplomáticos pelo Centro de Direito Internacional CEDIN (2013) e Mestre em Relações Internacionais pela Pontifícia Universidade Católica de Minas Gerais - PUC Minas (2018).
} 
fatores internos e externos que levaram a Alemanha a mudar a postura de sua política externa, passando da Realpolitilk da era bismarckiana para a Weltpolitik de Guilherme II?

Diante do exposto, entendemos ser importante compreender os fenômenos que permitiram, em algumas décadas, alçar a Alemanha ao status de grande potência. Uma combinação de fatores externos e internos deu ao novo país a oportunidade de aumentar o seu poder relativo, o que, por sua vez, viabilizou a busca por um novo posicionamento no sistema internacional através de uma mudança de rumo em sua política externa.

Partiremos do princípio de que houve dois momentos principais no que diz respeito à visão e à interpretação alemã do sistema internacional no período analisado. $\mathrm{O}$ primeiro momento se inicia após a unificação, com a chegada de Bismarck ao cargo de chanceler do novo Império, que entende que a manutenção do novo posicionamento relativo da Alemanha, estabelecido logo após a Guerra Franco-Prussiana, é essencial para os objetivos de política externa da Alemanha. O chanceler procura, por meio de tratados e acordos internacionais, manter o posicionamento alemão no sistema internacional, ao mesmo tempo em que busca a manutenção da paz, vista como fundamental para a promoção de uma coesão nacional. Configura-se, assim, a Realpolitik, que coloca o país rumo a um domínio político e diplomático da Europa.

O segundo momento desenvolve-se após a queda de Bismarck, em 1890, quando o novo kaiser, Guilherme II, deseja tomar para si o controle da política externa alemã. Muito influenciado pelos setores militares e pelos defensores de uma política externa mais agressiva e expansionista, o kaiser adota a Weltpolitik (Kitchen 2013; Berghahn 2005), uma política que, nas palavras de Bernhard von Bulow, permitiria que a Alemanha obtivesse seu "lugar ao sol". Em suma, deseja alcançar o protagonismo na distribuição mundial de poder, não mais se limitando à Europa.

Para compreendermos este processo, utilizaremos da perspectiva teórica do realismo neoclássico, que nos dará os instrumentos necessários para identificar como fatores internos e externos possibilitaram o crescimento internacional da Alemanha. Os autores desta escola "procuram explicar a grande estratégia de uma grande potência moderna em particular, em um período de tempo ou lugar específicos e não [em] padrões recorrentes de resultados políticos internacionais" (Taliaferro, Lobell, and Ripsman 2009, 6). ${ }^{1}$

\section{DO APARATO TEÓRICO — O REALISMO NEOCLÁSSICO}

A escola realista neoclássica pondera que, embora haja uma preponderância dos fatores sistêmicos, fatores internos também devem ser levados em consideração numa análise de relações internacionais. Dependendo 
da conjuntura e sob certas circunstâncias, tais fatores exercem influência significativa no sistema internacional como um todo ou em determinado episódio internacional.

De acordo com Gideon Rose (1998), o poder relativo dentro do sistema internacional é a variável independente que age em consonância a um conjunto de variáveis intervenientes: (1) a estrutura do Estado, (2) as capacidades do governo de extração e mobilização de recursos e (3) as percepções e cálculos dos líderes a respeito da distribuição do poder relativo.

Em primeiro lugar, portanto, os realistas neoclássicos apresentam uma concepção de Estado na qual as pressões sistêmicas direcionam seu comportamento externo. Enxergam o Estado como uma estrutura formada pelo governante e seus ministros, na qual são tomadas as decisões sobre política externa. Tal estrutura é o meio de ligação entre o Estado e a sociedade doméstica, tornando-se a instituição ideal e privilegiada no que diz respeito ao acesso à informação que orienta a leitura dos líderes cuja percepção dá o tom das ações externas.

Essa estrutura é pensada de tal maneira que as vontades do Estado sejam vistas pela população como "vontade nacional”. Se suas instituições são poderosas, maior será o controle e o domínio do Estado sobre a população, e maior será seu poder e influência. (Taliaferro, Lobell, and Ripsman 2009).

Em segundo lugar, Rose (1998) argumenta que "o escopo e a ambição da política externa de um país é direcionada, primeira e principalmente, pela sua posição no sistema internacional e, especificamente, por suas $c a$ pabilities de poder material relativo" (Rose 1998, 146). ${ }^{2}$ Entendidas como a habilidade do Estado em extrair e mobilizar recursos, direcionando-os para o desenvolvimento de sua política externa, são elas que definem a ambição internacional do Estado.

Para Jeffrey Taliaferro (2009), o poder relativo do Estado é derivado de suas capabilities que, por sua vez, são determinadas pelas instituições estatais e pelo controle das ideologias. Um Estado fortemente estruturado tem melhores condições de mobilizar e extrair recursos sociais. "Os Estados têm de ser capazes de realocar recursos sociais, que de outra forma seriam gastos em consumo, para a segurança e para as funções de condução de guerra. Variações nesta dimensão refletem diferenças institucionais entre países" (Rathbun 2008, 302). ${ }^{3}$

Finalmente, as percepções das lideranças dão o direcionamento da política externa. A leitura feita pelo governante da conjuntura internacional e das necessidades internas de seu país define seu padrão e diretrizes. Desta forma, "o Estado é uma variável interveniente entre o sistema internacional e a política externa” (Lobell 2009, 44). 
Portanto, as políticas externas de um Estado e as ações delas derivadas são resultado da percepção das lideranças estatais a respeito do poder relativo de seu Estado dentro do sistema internacional e, também, das leituras a respeito das demandas e exigências domésticas, que podem limitar suas ações no cenário internacional. As lideranças devem compreender quais as prioridades da sua população para poderem definir uma política, mas, por diversas vezes, recorrem a recursos estatais, estruturais (instituições públicas, bancos, investimentos em setores-chave, etc.) ou ideológicos (pressões políticas e trabalhistas; propagandas nacionalistas e institucionais), com o intuito de realizar objetivos de política externa. Assim, variáveis internas e externas afetam diretamente as escolhas políticas dos Estados (Taliaferro 2009).

\section{O PERÍODO BISMARCKIANO - AÇÕES DE POLÍTICA EXTERNA}

Após a conclusão do processo de Unificação da Alemanha, Otto von Bismarck visava a dois objetivos. Em primeiro lugar, buscava construir a ideia de nação alemã, o que daria uma coesão interna política e social ao Império e proporcionaria maior segurança no ambiente internacional, além de justificar, aos olhos do mundo, a existência de uma Alemanha unificada.

O segundo objetivo do chanceler era a preservação da paz no continente europeu, de forma que lhe fosse permitido dedicar esforços à construção da nação e à manutenção do posicionamento da Alemanha no sistema internacional, preservando-se o status quo construído logo após a Guerra Franco-Prussiana (Mulligan 2010).

Nesse sentido, a preservação da paz, a construção nacional da Alemanha e a manutenção do posicionamento internacional alemão estão intimamente conectados. Bismarck expôs suas ideias num documento conhecido como Memorando Kissingen, no qual enfatiza sua pretensão de alcançar " $[\ldots]$ uma situação política geral na qual todas as grandes potências, à exceção da França, tenham necessidade de nós e sejam mantidas o mais distante possível de uma potencial formação de coalizões contra nós" (Lerman 2010, 27). ${ }^{5}$ Tais ideias seriam a guia para o desenvolvimento da Realpolitik, para cuja execução o chanceler utilizou estratégias que envolveriam o uso de recursos internos e a diplomacia como arma política.

A percepção do líder de Estado sobre o ambiente internacional desempenha papel crítico no que diz respeito ao desenvolvimento da política externa (Taliaferro 2001; Rose 1998). Esta, por conseguinte, é formada de acordo com a avaliação do líder a respeito do poder relativo do seu Estado no sistema internacional, suas reais condições de extração e mobilização de recursos sociais, e da possível reação, intenção e percepção dos outros Estados (Taliaferro, Lobell, and Ripsman 2009). 
A leitura do sistema internacional feita por Bismarck levou-o a desenvolver as estratégias da Realpolitik. Primeiramente, a mudança de status da Alemanha não havia passado despercebida pelas grandes potências europeias. Pela primeira vez, os Estados alemães se mostravam unidos e fortes, levando Benjamin Disraeli, líder do Partido Conservador inglês, a declarar no Parlamento britânico que a vitória alemã na guerra Franco-Prussiana:

[...] representa a revolução alemã, um evento político maior que a revolução francesa do século passado. [...] Nenhum princípio na administração de nossos assuntos estrangeiros aceito como orientação por todos os estadistas até seis meses atrás existe mais. Não existe uma tradição diplomática que não tenha sido eliminada. Temos um novo mundo, novas influências no trabalho, novos e desconhecidos objetos e perigos com os quais lidar, atualmente envolvidos nesse obscuro incidente, novidade em tais assuntos. Nós costumávamos ter discussões nesta Câmara sobre o equilíbrio de poder. [...] Mas o que realmente aconteceu? O equilíbrio de poder foi inteiramente destruído e o país que mais sofre e sente os efeitos dessa grande mudança é a Inglaterra (Disraeli 1871, s.p.,). ${ }^{6}$

A Alemanha rompe com o status quo e o equilíbrio de poder na Europa, e começa a ser vista como uma ameaça pelas grandes potências europeias, como fica evidente no discurso de Disraeli, que receava que a nação recém-formada aspirasse a sonhos de crescimento à custa de seus vizinhos (Clark 2006; Lerman 2010; Mulligan 2010; Kitchen 2013).

Em segundo lugar, para Bismarck, era estritamente necessário o fortalecimento do sentimento nacional dentro do país. Sem a coesão interna proporcionada por tal sentimento, tornar-se-ia impossível a manutenção do poder e posicionamento relativos alemães no sistema internacional. A extração e mobilização de recursos sociais ver-se-iam dificultadas, já que não haveria harmonia entre os desejos estatais e os da sociedade. Nesse sentido, Bismarck identificaria dois inimigos internos do ideal nacionalista alemão: os sociais-democratas e as minorias nacionais. Moveu uma luta contra ambos, tanto no âmbito demagógico e da política, como de facto.

Em terceiro lugar, o chanceler percebia a fragilidade da posição geopolítica da Alemanha, cuja localização central no continente europeu poderia proporcionar um cerco de extensa magnitude caso houvesse a formação de uma coalizão hostil entre as potências europeias, algo que denominou de "pesadelo de coalizões" (Joll and Martell 2007; Lerman 2010). Segundo o chanceler,

Quando digo que é nosso dever esforçarmo-nos para estar prontos em todos os momentos e para todas as emergências, insinuo que devemos fazer maiores esforços do que outros povos para o mesmo 
propósito, devido à nossa posição geográfica. Estamos situados no coração da Europa e temos pelo menos três frentes abertas a um ataque (Bismarck 1888, s.p.,). ${ }^{7}$

Bismarck percebe que a Alemanha nada ganharia em ser vista como uma ameaça. Daí a necessidade de transmitir aos líderes europeus a imagem de uma nação que, embora formada a "ferro e sangue”, já se mostrava saciada. Sob esta ótica, a paz era condição sine qua non para que houvesse tempo necessário para a construção e o desenvolvimento da nação, para a segurança do Império e para a afirmação de seu status de potência europeia (Lerman 2010; Kitchen 2013).

Assim, o Império Alemão deveria provar às outras potências suas intenções pacíficas. Neste intuito, Bismarck utiliza de sua posição e influência nos meios diplomáticos. Sua atuação no Congresso de Berlim, em 1878, convocado com o interesse de evitar um conflito entre russos e austríacos nos Bálcãs e para o qual receava ser $\operatorname{arrastado}^{8}$ foi encarado pelos estadistas - ou assim Bismarck queria que pensassem - como uma clara manifestação do desejo alemão de preservação da paz, mas também como demonstração de poderio diplomático (Kennan 1985).

Em um documento datado de fevereiro de 1873, o embaixador britânico para a Alemanha, Odo Russell, escreve uma carta para o secretário de relações exteriores da Grã-Bretanha, Lorde Granville, descrevendo um encontro pessoal com Bismarck, que lhe deixa claras suas intenções pacíficas:

Ele [Bismarck] havia tido problemas e aborrecimentos suficientes para combater o desejo do imperador de anexar as províncias germânicas da Áustria, cuja população sem dúvida desejava fazer parte da grande família alemã, mas a este desejo ele se oporia enquanto estivesse no poder, já que ele preferia a aliança e a amizade da Áustria à anexação de províncias que em nada acrescentariam ao poder e segurança da Alemanha e cuja perda diminuiria o valor da Áustria como aliada.

Os suíços, por exemplo, formavam uma nação de língua alemã, mas a Suíça era de maior valor para Alemanha como um vizinho independente e amigo do que como uma província do Império Alemão (Russel 1873, s.p.,). ${ }^{9}$

Nesta carta, além do desejo manifesto de Bismarck em transmitir o desinteresse alemão por futuras anexações de território, já se pode entrever outro elemento da Realpolitik: a busca pela formação de alianças. Dadas as condições estruturais do sistema - a dificuldade de ter a Grã-Bretanha como aliada e a impossibilidade de uma aproximação com a França o chanceler não vê alternativa senão se aproximar de Rússia e Áustria- 
Hungria, cujos princípios conservadores eram compartilhados pelo chanceler (Kitchen 2013).

Entretanto, não foi só o aumento de poder relativo alemão que provocou perturbações no equilíbrio de poder. $\mathrm{O}$ declínio de potências tradicionais também foi importante para essa equação. A desconfiança internacional quanto ao poder material russo já vinha desde a Guerra da Crimeia e as posições de Áustria e França, fragorosamente derrotadas nas guerras de unificação da Alemanha, já denotavam perda de poder real. A França, por sinal, estava enfraquecida pelos pagamentos de reparação de guerra à Alemanha e ainda enfrentava intensa discórdia interna ${ }^{10}$ (Kitchen 2013). Há, portanto, uma movimentação na estrutura do sistema com a ascensão da Alemanha e a queda das potências supracitadas devido à variação do poder relativo. A Tabela 1, a seguir, nos dá uma ideia do desenvolvimento de cada potência europeia, indicando o crescimento do PNB de cada uma delas:

Tabela 1 - Volume do PNB, em dólar em 1960, em milhões, média de 10 anos, exceto para 1913

\begin{tabular}{c|c|c|c|c|c|c}
\hline Ano & Alemanha & Áustria & França & Grã-Bretanha & Itália & Rússia \\
\hline 1880 & 19.993 & 12.297 & 17.381 & 23.551 & 8.745 & 23.250 \\
\hline 1890 & 26.454 & 15.380 & 19.758 & 29.441 & 9.435 & 21.180 \\
\hline 1900 & 35.800 & 19.400 & 23.500 & 36.273 & 10.820 & 32.000 \\
\hline 1910 & 45.523 & 23.970 & 26.869 & 40.623 & 12.598 & 48.830 \\
\hline 1913 & 49.760 & 26.050 & 27.401 & 44.074 & 15.624 & 52.420 \\
\hline
\end{tabular}

Fonte: Mulligan (2010).

Embora ocupasse posição preponderante entre as grandes potências, o posicionamento relativo alemão não pode ser considerado estável. É, na verdade, bem frágil, dadas a instabilidade interna do novo Império e a desconfiança por parte das outras potências.

A alternativa encontrada por Bismarck para preservar a posição da Alemanha no sistema internacional foi a formação de alianças que a manteriam sempre em um bloco composto por, no mínimo, três potências. Como destaca Randall Schweller (2008), alianças são formalizadas quando um país objetiva a manutenção ou a ruptura de uma dada conjuntura. Como vimos, era interesse da Alemanha a manutenção do status quo de momento.

A Áustria-Hungria estava ciente de sua fragilidade, especialmente devido à sua formação política que compunha diversas nacionalidades. Uma nova ruptura na balança de poder poderia provocar uma séria e prova- 
velmente insolúvel instabilidade interna. Nesse sentido, uma ajuda aliada poderia ser necessária.

A Rússia ainda se enxergava como uma potência de primeiro escalão ${ }^{11} \mathrm{e}$ via na Alemanha uma aliada natural, dados os vínculos dinásticos entre elas e o longo histórico de cooperação e neutralidade cordial ${ }^{12}$ (Kitchen 2013).

Desta forma, as alianças foram ferramentas importantes para se atingir o objetivo da estabilidade externa necessária para o desenvolvimento do processo de construção da nação alemã. "Elas serviram para a segurança do Reich e para a preservação da paz na Europa, dois objetivos virtualmente indistintos para a mente de Bismarck" (Mulligan 2010, 26-27). ${ }^{13}$

Segundo Katherine Lerman (2010), o grande insight de Bismarck foi compreender o aspecto multipolar das relações internacionais na Europa e entender como as relações bilaterais empreendidas pela Alemanha poderiam influenciar, inclusive, nas ações e objetivos de terceiros. O desenvolvimento da política de alianças centradas em Berlim foi posto como meio para atingir os objetivos de "interesse nacional”, de forma que a manipulação, por parte de Bismarck, das relações entre os países, provocasse reações em terceiros.

\section{O Período Bismarckiano — Ações Internas}

O projeto de construção da nação alemã havia apenas começado com a conclusão da Unificação. Nesse sentido, um Estado forte e coeso era fundamental, e Bismarck “[ [...] esperava que os partidos políticos que considerava 'amigos do Império' formassem uma firme coalizão nacional” (Kuhne 2010, 182). ${ }^{14}$

O primeiro passo para a consolidação do Estado foi a elaboração de uma Constituição que delegava grandes poderes ao kaiser e ao chanceler. Bismarck procurou fortalecer e ampliar o alcance das instituições do Estado, o que daria à Alemanha a coesão interna necessária para lhe permitir desempenhar um papel de destaque na esfera internacional.

Segundo Jeffrey Taliaferro (2009), o poder do Estado é diretamente derivado da força de suas instituições, o que permite aos líderes maior capacidade de extração e mobilização de recursos sociais. A Constituição do Reich é exemplar neste aspecto, ao vincular as forças armadas e as decisões de política externa ao controle direto do soberano.

Entretanto, as instituições políticas previstas na Constituição eram difíceis de serem controladas, especialmente o Reichstag, que, eleito por voto masculino universal, provocava verdadeiros pesadelos em Bismarck e nos chanceleres que o sucederam.

Um subterfúgio constitucional criou a possibilidade de dissolução do Reichstag e convocação de novas eleições, com o objetivo de obter um par- 
lamento mais alinhado aos objetivos dos líderes do Estado. Certamente, esse poder era conferido ao kaiser, mas a influência do chanceler não raro convencia o soberano a fazer uso deste artifício. Como nos lembra Volker Berghahn (2005) a respeito da preponderância de Bismarck sobre as decisões políticas, é fato que a Constituição

[...] fazia o chanceler dependente do monarca, que poderia dispensá-lo a qualquer momento. Mas, na verdade, a relação entre Guilherme I e o seu chanceler foi gradativamente se revertendo. Ao contrário de seu filho e de seu neto, este kaiser não estava particularmente interessado em governar pessoalmente; portanto, na maioria dos casos, ele se sentia feliz em seguir a liderança e os conselhos de Bismarck. (Berghahn 2005, 182-3). ${ }^{15}$

O segundo passo dado por Bismarck foi a identificação de inimigos internos, promovendo uma perseguição institucionalizada a católicos e socialistas exemplificada pela lei antijesuíta, de quatro de julho de 1872, que bania da Alemanha a Ordem dos Jesuítas, dando início à Kulturkampf, ou "batalha cultural"; e pela lei antissocialista de 21 de outubro de 1878, por meio da qual ficaram proibidas quaisquer associações, encontros e jornais de cunho social-democrata.

Ao apontar os inimigos da nação alemã, o chanceler faz apelo à questão da segurança nacional e ao nacionalismo, instigando tal sentimento na população. Através de ações como essas, assim como a intensificação de políticas públicas educacionais de exaltação aos feitos do passado sobre a construção do Império (Chickering 2010), percebemos que o nacionalismo exaltado alemão de fins do século XIX está intimamente ligado à atuação política do Estado.

A identidade entre a formação nacional e o Estado fornece os elementos ideais para facilitar a extração e mobilização de recursos sociais (Taliaferro 2009). Coesão nacional não significa unanimidade política, mas um sentimento de pertencimento a um determinado país, uma identificação sociocultural proporcionada pela língua, pela educação, pela cultura e pelo Estado, responsável por desenvolver a força-motriz necessária para que a população ultrapasse obstáculos e diferenças regionais, políticas, étnicas e/ou econômicas de forma que se mobilizem em prol de um objetivo mais amplo e de cunho nacional. Assim, um processo de "germanização" foi instaurado por Bismarck nas regiões onde minorias nacionais (poloneses, franceses, dinamarqueses) se aglutinavam.

Com o apoio dos Nacionalistas Liberais, que acreditavam na formação de uma nação baseada na língua e na etnia, foram implementadas medidas que decretavam o alemão como a única língua a ser ensinada nas esco- 
las (1873) e a ser usada nas repartições administrativas públicas (1876) e nas cortes judiciárias (1877). Ademais, implementou-se um programa de compras de terra que visava distribuir a alemães terrenos pertencentes a poloneses (Berghahn 2005; Lerman 2010).

O socialismo também se estruturou fortemente na Alemanha do século XIX. O Partido da Social-Democracia Alemã (SPD), em detrimento da perseguição sofrida, tornar-se-ia o maior e mais importante partido socialista da Europa. Baseava-se no conceito marxista de luta de classes e se apoiava largamente no poder das massas, especialmente nos trabalhadores assalariados das cidades cujo número crescia em ritmo acelerado paralelamente ao intenso processo de urbanização e industrialização do Império (Berghahn 2005).

Bismarck, percebendo a força do movimento, tenta angariar seu apoio ao estabelecer uma legislação de seguridade social. Acreditava que, com a implementação de medidas que a beneficiasse, a massa trabalhadora (que detinha poder de voto graças ao artigo constitucional que estabelecia o voto universal masculino) reconheceria a benevolência do Estado alemão e dele se aproximaria, afastando-se, portanto, do socialismo. Durante seu período como chanceler, foram aprovadas leis de "bem-estar social” que, em 1883, previam compensações ao trabalhador durante enfermidade; em 1884, ditava regras de seguro em caso de acidente de trabalho; e em 1889, introduzia pensões para trabalhadores acima de 70 anos de idade, dando um primeiro passo rumo a uma espécie de previdência social. A implementação de tais leis conferiria mais poder ao Estado que, nos anos 1880 , conseguiria se desvencilhar da necessidade do apoio dos liberais (Lerman 2010).

A atuação de Bismarck ao manter o Reichstag sob controle e ao saber utilizar as ideologias que se desenvolviam na Alemanha em proveito do fortalecimento do Estado, proporcionou a coesão entre os objetivos da sociedade e o "interesse nacional”, essencial para que pudesse garantir autonomia de ação no nível doméstico e internacional.

\section{O PERÍODO GUILHERMINO — AÇÕES DE POLÍTICA EXTERNA}

Após a queda de Bismarck, o imperador Guilherme II, que subiu ao trono em 1888, toma para si as rédeas do Estado. Guilherme tenta exercer maior controle sobre o desenvolvimento da Alemanha, dando ouvidos aos anseios de setores cuja importância aumentava com o crescimento alemão, em especial a burguesia industrial, militares e colonialistas.

Isso levaria a uma alteração na percepção do sistema internacional, provocando uma importante mudança na política externa alemã. Doravante, 
procurava-se encontrar para a Alemanha um lugar de destaque na distribuição de poder não apenas na Europa, mas no mundo, dando início à Weltpolitik.

A Weltpolitik faz parte de um contexto mais amplo de políticas expansionistas executadas por diversos países naquele momento. A chegada de novos atores a esta corrida ${ }^{16}$ era regra, não exceção (Hobsbawn 2016). Entretanto, é difícil dizer se a Weltpolitik teria sido o desfecho desejado por Bismarck, mas não seria absurdo observar que ele, ao procurar assegurar a posição da Alemanha nas décadas imediatamente posteriores à unificação e enfatizar o desenvolvimento de uma coesão nacional, antevia essa possibilidade como uma realidade se não provável, possível.

Assim sendo, o que possibilitou o desenvolvimento da Weltpolitik, uma política externa ambiciosa e agressiva que visava mudar os rumos da política externa alemã?

Primeiramente, Guilherme II e seus assessores ambicionavam novas possibilidades para o Império, algo que a Realpolitik, com sua ideia de contenção, não permitia. $O$ novo imperador faria valer suas prerrogativas constitucionais para desenvolver uma política internacional que representasse a modernidade de uma era, dando voz aos setores burgueses e industriais rumo ao expansionismo (Clark 2009).

Um comentário do kaiser, no ano de 1900, demonstra seu tom beligerante e o desejo de ser um imperador "independente":

Nenhuma grande decisão pode ser tomada agora sem que se consulte o Império Alemão e o kaiser...

A Coroa envia seus raios através da "graça de Deus" para dentro de palácios e cabanas, e - me desculpem por ousar dizer - a Europa e o mundo escutarão com atenção "o que diz e pensa o imperador alemão”, e não qual é a vontade de seu chanceler!... Pois sempre haverá apenas um verdadeiro imperador no mundo, e este é o kaiser alemão, desconsiderando sua pessoa e seus traços, sozinho por direito de uma tradição de mil anos, e o seu chanceler deve obedecer! (Williamson Jr. and Van Wyck 2003, 77). ${ }^{17}$

Em segundo lugar, os principais expoentes da Weltpolitik, o chanceler Bernhard von Bulow e o almirante Alfred von Tirpitz, encontravam apoio para suas propostas expansionistas nas diversas associações nacionalistas que surgiam pela Alemanha de Guilherme II (ver Tabela 2). Essa base de apoio era formada por diversos grupos da burguesia educada, constituída por intelectuais que acreditavam no benefício étnico de uma expansão alemã dada a supremacia da etnia germânica, formando um grupo coeso de- 
fensor do darwinismo social. Também encontravam suporte entre industriais e empresários, para quem o acesso ao mercado mundial prometido pela "política mundial” era deveras atraente (Conrad 2010).

Tabela 2

Membros das Associações Nacionalistas, 1881-1914

\begin{tabular}{l|c|c|c}
\hline Ano & Liga Pangermânica & Liga da Marinha & Sociedade Colonial \\
\hline 1881 & & & \\
\hline 1887 & & & 14.838 \\
\hline 1891 & 21.000 & & 17.709 \\
\hline 1893 & 5.000 & & 17.154 \\
\hline 1894 & 5.742 & & 16.264 \\
\hline 1895 & 7.715 & & 16.474 \\
\hline 1896 & 9.443 & & 17.901 \\
\hline 1897 & 12.974 & 14.252 & 21.252 \\
\hline 1898 & 17.364 & 93.991 & 26.501 \\
\hline 1899 & 20.488 & 216.749 & 31.601 \\
\hline 1900 & 21.735 & 238.767 & 34.768 \\
\hline 1901 & 21.924 & 233.173 & 33.541 \\
\hline 1903 & 19.068 & 249.241 & 31.482 \\
\hline 1904 & 19.111 & 315.420 & 31.985 \\
\hline 1906 & 18.445 & 290.964 & 32.787 \\
\hline 1910 & $\mathrm{x}$ & 320.174 & 39.025 \\
\hline 1912 & $\mathrm{c} .17 .000$ & 331.493 & 41.163 \\
\hline 1914 & $\mathrm{x}$ & & 42.018 \\
\hline
\end{tabular}

Fonte: Berghahn (2005).

Em terceiro lugar, é difícil vislumbrar a Weltpolitik sem o que talvez tenha sido o maior legado deixado por Bismarck: a coesão interna. O que outrora, logo após a conclusão do processo de unificação do Império, se mostrava como algo ainda por se formar, "[ [...] para a maioria dos contemporâneos, a legitimidade do Império Alemão já era incontestável em 1890” (Hewitson 2010, 44). ${ }^{18}$

Em quarto lugar, o crescimento econômico alemão ainda era notável quando comparado ao de outras potências europeias, inclusive a GrãBretanha, que, neste período da virada do século XIX para XX, atravessava um momento de declínio relativo (Friedberg 2010; Hobsbawn 2016). 
Finalmente, a Constituição do império ligava as forças armadas diretamente ao kaiser e Guilherme II tinha real apreço pela história militar da Alemanha, valorizando sobremaneira os conselhos de seu staff militar. O militarismo alemão seria usado como ferramenta da Weltpolitik, que previa o desenvolvimento do programa naval, a reforma do programa militar alemão e o recrudescimento dos investimentos militares (criação de novos regimentos, incentivo ao desenvolvimento bélico, aumento do número de anos do serviço militar, etc.), conforme podemos observar na Tabela 3, a seguir:

Tabela 3

Gastos militares das grandes potências (em milhões de libras)

\begin{tabular}{c|c|c|c|c|c|c}
\hline Ano & Alemanha & Áustria & França & $\begin{array}{c}\text { Grã- } \\
\text { Bretanha }\end{array}$ & Itália & Rússia \\
\hline 1900 & 43,2 & 11,4 & 41,5 & 69,6 & 14,1 & 44,5 \\
\hline 1906 & 57,1 & 13,7 & 46,2 & 62,2 & 14,8 & 100,3 \\
\hline 1911 & 68,1 & 17 & 60,8 & 67,8 & 22,9 & 71 \\
\hline 1912 & 72 & 20,6 & 62,8 & 70,5 & 29,9 & 86,2 \\
\hline 1913 & 93,4 & 25 & 72 & 72,5 & 39,6 & 101,7 \\
\hline
\end{tabular}

Fonte: Mulligan (2010).

O poder material é essencial para se compreender o poder e o posicionamento relativos de uma potência no sistema internacional, e o desenvolvimento do potencial militar é uma das principais variáveis a serem consideradas (Taliaferro 2009). É notável que em menos de 15 anos o investimento alemão no setor militar tenha mais do que dobrado. Por outro lado, os gastos militares das demais potências, à exceção da Rússia, não tiveram aumento semelhante.

Jeffrey Taliaferro (2009) sustenta que cabe aos Estados optar de que maneira responderão às pressões: se através da emulação ou da inovação. No caso da Alemanha de Guilherme II, fez-se a opção pela emulação de uma prática de sucesso no que diz respeito à obtenção de objetivos imperialistas: a formação de uma forte marinha de guerra. O grande exemplo histórico era a Grã-Bretanha, que expandira seu império com base no controle dos mares e oceanos por sua armada.

Taliaferro (2009) ainda enfatiza que os Estados que buscam a emulação normalmente são aqueles que possuem grande capacidade de extração e mobilização de recursos sociais, mas que não desfrutam de uma posição 
confortável no sistema internacional. Com o Estado fortemente estruturado, mas com frágil posicionamento no sistema internacional, a Alemanha configura-se como estudo de caso exemplar neste aspecto.

Colocada em prática, a Weltpolitik aciona o gatilho que a torna uma política ambivalente ao procurar a obtenção de uma posição como potência mundial e a defesa de sua posição na Europa (Mulligan 2010). Explicamos: a formação da aliança franco-russa no início da década de 1890 coloca a Alemanha defronte um perigo que jamais fora superado: o risco de uma guerra em duas frentes. A Alemanha deve se contentar com o apoio da Grã-Bretanha, ou pelo menos com a neutralidade e a costumeira política de isolamento desta última, em um eventual conflito. Entretanto, contraditoriamente, a principal ferramenta da Weltpolitik era a política naval que provocava os britânicos diretamente. Martin Kitchen (2013) resume a situação:

[…] a Alemanha precisava do apoio da Grã-Bretanha na Europa contra a ameaça da Rússia e da França, mas as suas aspirações imperiais tornavam difícil consegui-lo. A Alemanha queria garantir a sua segurança na Europa ao mesmo tempo em que perseguia uma vigorosa Weltpolitk. Alguns poucos dos que ocupavam posições de autoridade se deram conta de que essas ambições eram contraditórias (Kitchen 2013, 240).

Contraditória e mesmo assim levada a cabo, a Weltpolitik foi colocada em prática de fato com a aprovação, pelo Reichstag, do primeiro projeto de lei naval do almirante Tirpitz, em março de 1898 (Clark 2009). Novas leis, que intensificaram os investimentos e ampliaram ainda mais o tamanho da armada, foram aprovadas em sequência pelo Reichstag nos anos de 1900, 1906, 1908 e 1912 (Clark 2009, 187). Guilherme II não conteve esforços para a aprovação dessas leis. Num telegrama endereçado ao chanceler do Império, em 1899, o imperador não mediu suas palavras:

Sua Excelência está ciente de que eu estou firmemente determinado a dissolver o Reichstag caso este rejeite o reforço dos nossos armamentos navais, tão absolutamente vitais para nossa segurança e nosso futuro. Todas as outras preocupações devem estar subordinadas a esta questão, que é um problema de importância existencial para o Reich (Clark 2009, 187). ${ }^{19}$

O gabinete naval criou o departamento de propaganda que, através de uma série de estratagemas (plantar artigos em jornais, pagamento de professores para falar em benefício da marinha e apoio à Liga Naval Alemã), conseguiu concentrar o sentimento público na necessidade de construção de uma poderosa marinha de guerra. Nesse sentido, essa intensa ação propagandística 
foi uma maneira eficiente de extração de recursos sociais, na medida em que pressiona o parlamento e faz apelo ao apoio da população a uma política de Estado, identificando os interesses do povo alemão aos "interesses nacionais".

Assim, o sonho imperialista alemão se tornara algo muito popular em diversos setores da sociedade. Cidadãos liberais como Max Weber e Friedrich Naumann acreditavam que uma aventura imperialista poderia desgarrar a Alemanha do domínio das elites conservadoras, e até mesmo alguns socialistas enxergavam benefícios nessa expansão imperialista, na medida em que poderia levar as ideias progressistas à periferia mundial (Kitchen 2013).

Entretanto, a Grã-Bretanha responde à política naval alemã por meio do apoio estatal ao desenvolvimento de novas tecnologias navais, especialmente a da nova classe de encouraçado de guerra, o Dreadnought (Berghahn 2005). Na Grã-Bretanha, o controle dos mares era realmente considerado fundamental para sua existência; não era mera demagogia.

Ademais, o desafio imposto pela Alemanha faz com que a Grã-Bretanha cogite abandonar seu "esplêndido isolamento" e procure estreitar as relações com França e Rússia. Este movimento segue a cartilha do realismo neoclássico de formação de alianças conforme explicado por Schweller (1998), segundo a qual os Estados satisfeitos formariam alianças tendo em vista a manutenção do seu posicionamento relativo no sistema internacional. Para a Grã-Bretanha, o que importava era a ausência de uma potência hegemônica e agressiva na Europa e, principalmente, a manutenção de sua posição no sistema internacional global.

Assim sendo, o principal e mais ambicioso passo da Weltpolitik pode ser considerado um desastre. Sua implementação acaba por fragilizar ainda mais o posicionamento relativo da Alemanha. A soberba alemã e sua busca implacável por um "lugar ao sol" a colocam em conflito com potências tradicionais, que não viram alternativas senão dirimir suas divergências históricas e formarem entre si uma coalizão de forma a combater um rival que se mostrava ambicioso e por demais poderoso.

\section{O Período Guilhermino — Ações Internas}

Guilherme II coadunava do pensamento daqueles que afirmavam que a Alemanha, sob Bismarck, atuava abaixo de seu potencial econômico, tecnológico e militar. Tendo em vista a implementação da Weltpolitik, busca o apoio das principais classes políticas da Alemanha e age de forma a beneficiar tanto a burguesia industrial, motor que propulsionava a política mundial alemã, quanto os Junkers (aristocracia prussiana composta principalmente por proprietários de terras) que, embora tivessem perdido poder 
econômico, ainda detinham enorme prestígio, poder político e influência nas decisões do Reichstag (Fairbairn 2010).

Econômica e financeiramente, Guilherme II deveria encontrar um meio de arrecadar insumos que lhe permitissem desenvolver a Weltpoplitik, ou seja, que pagasse a construção de sua armada, proporcionasse as condições de instalação e formação de colônias alemãs e que provesse o Estado com os recursos necessários para bancar investimentos externos.

Segundo Jeffrey Taliaferro (2009), a extração e mobilização de recursos podem ser feitas por meio de um planejamento centralizado, nacionalização de indústrias-chave ou através da atuação de empresas nacionais. $\mathrm{O}$ primeiro passo de Guilherme foi buscar o apoio para aprovação das políticas no Reichstag, obtido através de ações que interessavam diretamente aos principais setores detentores do poder político. A abertura comercial de produtos industrializados favoreceu o setor burguês-industrial, e o subsídio às exportações e tarifas protecionistas de produtos agrícolas agradaram o setor agrário (Fairbairn 2010).

Em 1878, as ferrovias prussianas foram nacionalizadas, o governo subsidiou o treinamento de pessoal para melhor capacitação dos empregados das indústrias e investiu no transporte público das cidades (Fairbairn 2010). De forma a facilitar o escoamento da produção interna, em 1905 foi concluída a construção de um sistema de canais que conectavam os principais rios do país.

Houve um intenso investimento no desenvolvimento de tecnologias e indústrias nacionais. O próprio Guilherme II era um entusiasta do desenvolvimento tecnológico, direcionando pesadas somas à educação, à pesquisa científica e tecnológica. Fazia frequentes intervenções pessoais em setores que considerava chave e de "interesse nacional” (Clark 2009). Na Tabela 4, notamos um importante aumento dos investimentos em ciências não apenas no nível federal, mas também nos principais entes do Império.

\section{Tabela 4}

Aumento nos gastos em ciências pelo Reich e pelos maiores estados federados em médias de 10 anos

\begin{tabular}{c|c|c|c|c|c}
\hline Anos & Reich & Prússia & Bavaria & Saxônia & Baden \\
\hline $1870-79$ & 2,3 & 10,4 & 2,8 & 1,4 & 1,3 \\
\hline $1880-89$ & 5,1 & 15,7 & 3,5 & 1,9 & 1,8 \\
\hline $1890-99$ & 7,6 & 18,8 & 4,3 & 3,2 & 2,7 \\
\hline $1900-09$ & 15,0 & 35,9 & 6,3 & 4,2 & 3,7 \\
\hline $1910-14$ & 18,8 & 50,1 & 10,3 & 6,6 & 4,8 \\
\hline
\end{tabular}

Fonte: Berghahn (2005). 
$\mathrm{O}$ apoio estatal às empresas se dava financeiramente e através de políticas que projetavam seu crescimento internacional, favorecendo a exportação de seus produtos e protegendo-os internamente da competição com produtos importados. Tais políticas auxiliaram a transformar a Alemanha de um Estado agrário com uma forte indústria, em um Estado industrial com uma forte agricultura (Berghahn 2005; Fairbairn 2010).

Empresas como Thyssen, Krupp, Siemens e Basf, grandes responsáveis pelo desenvolvimento de tecnologia bélica, estavam profundamente interessadas na Weltpolitik e, não por acaso, estão entre as que mais se beneficiaram dela (Fairbairn 2010). Externamente, a presença de produtos, bancos e empresas alemãs no mercado mundial prometia a chance de exercer forte influência nas tomadas de decisão que poderiam significar aliança internacional e/ou apoio em eventual conflito. ${ }^{20}$

Outra maneira de se extrair e mobilizar recursos, segundo Taliaferro (2009), seria através da intervenção indireta na economia nacional, aplicando novas taxas e criando novos impostos de modo a financiar o crescimento do poder militar. "Tarifas e impostos aumentaram durante a era guilhermina, a fim de financiar maiores gastos com forças armadas, administração e seguridade social" (Hewitson 2010), ${ }^{21}$ como nos exemplificam a lei naval de 1898 e suas seguidas reformas.

No entanto, para além do aspecto econômico e financeiro, a promoção de uma política do porte e ambição da Weltpolitik se tornaria impossível caso não houvesse coesão social interna. Alguns fatores ligados à promoção das ideologias ajudam a explicar o aumento do apoio popular e a identificação dos anseios da sociedade aos objetivos do Estado.

A ideia do nacionalismo na Alemanha imperial sempre andou de mãos dadas com questões militares e de educação. No período Guilhermino, houve um estreitamento entre as temáticas, em particular do militarismo - Roger Chickering (2010, 201) chega a mencionar uma "cultura militarizada do patriotismo", ${ }^{22}$ graças especialmente ao desenvolvimento e ao crescimento da influência de grupos de pressão, as já mencionadas ligas.

O Estado, aliás, foi um dos responsáveis pela militarização da cultura alemã (Chickering 2010) e promoveu uma militarização sistêmica dos símbolos do Império. A canção Deutschland uber Alles (a Alemanha acima de todos) transformou-se no hino nacional (Hobsbawn 2016) e no dia dois de setembro, data da vitória da Prússia sobre a França, em Sedan, era celebrado o dia nacional da Alemanha.

Essa cultura patriota era desde cedo estimulada pelo Estado. Embora o sistema educacional tenha permanecido nas mãos dos Estados federados após a unificação, desde o período de Bismarck o Império intervinha diretamente no ensino público e particular. Os currículos foram atualizados 
enfatizando a construção nacional, na qual os campos de batalha das guerras de unificação se tornaram o ápice do ensino de História. Nas escolas públicas eram realizadas celebrações patrióticas em datas comemorativas com o intuito, de acordo com as palavras de um oficial prussiano, de já “[...] cultivar nas crianças 'o poderoso estímulo de imitar seus pais', os veteranos da guerra de 1870-1871, que tinham 'arriscado tudo para assegurar as maiores bênçãos terrestres para seus descendentes”' (Chickering 2010, 200)..$^{23}$

Em uma ordem dirigida ao Ministro de Estado Prussiano, em 1889, Guilherme II afirma que a grade curricular deveria dar mais relevância a acontecimentos mais recentes e contemporâneos, em uma clara referência à valorização das guerras de unificação (Clark 2009). Em um discurso público, declarou que o sistema escolar alemão deveria valorizar “[ [...] a higiene, a educação física, a redução da carga de estudos e a necessidade de uma base nacional para o currículo. Os objetivos eram claros: o exército deveria ser provido de jovens fortes" (Clark 2009, 83). ${ }^{24}$

Desta forma, o Estado consegue influenciar ideologicamente a formação dos jovens alemães, criando uma base nacionalista e militarizada que responderia mais fácil aos seus anseios, na medida em que haveria maior facilidade na identificação dos interesses da sociedade junto aos "interesses nacionais" conforme compreendidos pelo Estado.

\section{CONCLUSÕES}

Uma análise do sistema internacional entre 1871-1914 nos mostrou que havia um vazio provocado pelo declínio relativo de algumas potências nas últimas décadas do século XIX. A Alemanha tentou ocupar este vazio, procurando, sob a batuta de Bismarck, a manutenção da balança de poder europeia, que se lhe tornou favorável após 1871. A partir deste momento, na medida em que as grandes potências reconhecem o aumento do poder relativo alemão, a Alemanha passa a ter voz ativa nas reuniões diplomáticas e congressos internacionais, guiada pela luz da Realpolitik de Bismarck, cujo respeito, admiração e temor junto aos seus pares fez com que fosse considerado a principal figura política da Europa naquele período.

Já sob a liderança de Guilherme II, alguns elementos, como o relativo declínio da Grã-Bretanha na virada do século e o fortalecimento da coesão interna da Alemanha, permitiram uma mudança na percepção da conjuntura internacional, o que fez com que a política externa alemã mudasse seus objetivos e partisse para uma diretriz mais arriscada, procurando expandir sua influência por meio do desenvolvimento de uma política imperialista e armamentista. 
Fatores internos ajudam a explicar essa mudança de rumo no âmbito internacional. Primeiramente, a subida ao poder de uma personalidade como Guilherme II, que busca manter sob seu controle as decisões sobre política externa e forças armadas. Em segundo lugar, a pressão exercida pelos militares e barões da indústria, interessados em uma expansão internacional, nos moldes já aplicados por potências como Grã-Bretanha e França. Em terceiro lugar, a presença de associações nacionalistas, grupos industriais e imperialistas que viam na necessidade da ampliação do Império ultramarino alemão uma forma de demonstração do poder nacional do país. A Weltpolitik surge também como uma válvula de escape para as pressões exercidas por elas.

A soma destes fatores internos e externos nos dá a mudança de percepção por parte do Estado alemão quanto ao seu posicionamento relativo no sistema internacional. Sob Bismarck, o receio de entrar em conflito em uma guerra em duas frentes deu o tom da política externa, que buscava a manutenção da paz como forma de promover a coesão interna e nacional da Alemanha, sem perder de vista a manutenção da posição alemã de potência europeia.

Sob Guilherme II, uma nova percepção foi formada: a Alemanha já havia conseguido desenvolvimento, coesão e potencial internos suficientes para buscar novos caminhos, alçar voos mais ambiciosos, que condissessem com seu poder na Europa, e entrar na partilha do mundo. De fato, o discurso de Bernhard von Bulow sobre "o lugar ao sol" para o povo alemão é revelador desta noção de um direito, quase que divino, de que cabia, também à Alemanha, um posto de potência imperialista detentora de colônias. $\mathrm{O}$ desenvolvimento de uma política de expansão naval é sintoma desse novo rumo da política externa implementada por Guilherme II.

Fareed Zakaria (1998), ao realizar um estudo sobre os Estados Unidos na virada do século XIX para o XX, concluiu que o país abandona sua política de não envolvimento com questões imperialistas fora do continente americano porque compreende que a sua capacidade de extração e mobilização de recursos aumentou.

Chegamos, neste artigo, a conclusão semelhante: na década de 1890, Guilherme II percebe que há coesão interna suficiente para a implementação de uma política externa mais ambiciosa. Através de uma intensificação dos meios que lhe possibilitarão angariar recursos com maior facilidade, promove uma mudança no comportamento externo da Alemanha. Outrora defensor do pragmatismo da Realpolitik, o país se vê implementando as ambições da Weltpolitik. Tal mudança de comportamento só foi possível porque houve um aumento do poder do Estado alemão, proporcionado pelo aumento de sua capacidade de extração e mobilização de recursos sociais. 
A Weltpolitik dificilmente poderia ter existido sem a Realpolitik. Elas se complementam. A estabilização doméstica e internacional promovida por Bismarck permitiu a Guilherme II e seus chanceleres a implementação de uma política expansionista. Altamente influenciada por uma questão de prestígio internacional da nação, a Alemanha entra na corrida imperialista ambicionando dar o passo seguinte no sentido de aumentar seu poder relativo no sistema internacional global e tornar-se, em última instância, uma potência de nível mundial.

\section{REFERÊNCIAS}

Alemanha. 1871. Constituição do Império Alemão de 1871. His Majesty the King of Prussia in the name of the North German Federation, His Majesty the King of Bavaria, His Majesty the King of Wïrttemberg, His Royal Highness the Grand Duke of Baden and His Royal Highness the Grand Duke of Hesse and by Rhine... Reichsgesetzblatt, Berlim. http://germanhistorydocs.ghi-dc.org/sub_document.cfm?document_ id $=1826$.

1878. Lei Antissocialista de 21 de outubro de 1878. Lei contra os esforços publicamente perigosos da Social-Democracia. Reichsgesetzblatt, Berlim. http://germanhistorydocs.ghi-dc.org/sub_document.cfm?document_id=1843.

Berghahn, Volker. 2005. Imperial Germany: economy, society, culture and politics 1871-1914. New York: Berghahn Books.

Bismarck, Otto von. 1862. A Ferro e Sangue. Discurso. http://germanhistorydocs. ghi-dc.org/sub_document.cfm?document_id=250.

1866. Preceitos de Putbus sobre a Constituição Alemã. Memórias. http://germanhistorydocs.ghi-dc.org/docpage.cfm?docpage_id=2870.

. 1886. A Questão Polonesa. Discurso. http://germanhistorydocs.ghi-dc.org/ docpage.cfm?docpage_id=2888.

1888. Nós, alemães, tememos a Deus e a nada mais no Mundo. Discurso. http://germanhistorydocs.ghi-dc.org/sub_document.cfm?document_id=1865.

S/D. Pesadelo de Coalizões. Memórias. http://germanhistorydocs.ghi-dc. org/sub_document.cfm?document_id=1855.

Bulow, Bernhard von. 1897. Por um Lugar ao Sol. Discurso. http://germanhistorydocs.ghi-dc.org/sub_document.cfm?document_id=783. 
. 1899. Uma Política Externa Dinâmica. Discurso. http://germanhistorydocs.ghi-dc.org/sub_document.cfm?document_id=779.

Canfora, Luciano. 2014. 1914. São Paulo: EDUSP.

Chickering, Roger. 2010. "Militarism and Radical Nationalism". In Imperial Germany: 1871-1918, edited by James Retallack, 196-218. Oxford: Oxford University Press.

Clark, Christopher. 2006. Iron Kingdom: the rise and downfall of Prussia. Londres: Penguin Books. . 2009. Kaiser Wilhelm II: a life in power. Londres: Penguin Books. 2014. Os Sonâmbulos: como eclodiu a Primeira Guerra Mundial. São Paulo: Companhia das Letras.

Conrad, Sebastian. 2010. “Transnational Germany”. In Imperial Germany: $1871-$ 1918, edited by James Retallack, 219-41. Oxford: Oxford University Press.

Crowe, Eyre. 1907. Percepções sobre a política externa alemã na Inglaterra. Memorando. http://germanhistorydocs.ghi-dc.org/sub_document.cfm?document_id=784.

Disraeli, Benjamin. 1871. Disraeli sobre a "Revolução Alemã". Discurso. http://germanhistorydocs.ghi-dc.org/sub_document.cfm?document_id=1849.

Fairbairn, Brett. 2010. Economic and Social Developments. In Imperial Germany: 1871-1918. Edited by James Retallack, 61-82. Oxford: Oxford University Press.

Friedberg, Aaron. 2010. The Weary Titan: Britain and the experience of relative decline (1895-1905). Princeton: Princeton University Press.

Herwig, Holger H. 2008. "Why did it Happen?" In The Origins of World War I, edited by Richard F. Hamilton. and Holger H. Herwig, 443-68. New York: Cambridge University Press.

Hewitson, Mark. 2010. “Wilhelmine Germany”. In Imperial Germany: 1871-1918, edited by James Retallack, 40-60. Oxford: Oxford University Press.

Hobsbawn, Eric J. 2016. A Era dos Impérios: 1875-1914. Rio de Janeiro: Paz e Terra.

Joll, James, and Gordon Martell. 2007. The Origins of the First World War. Londres; Nova Iorque: Routledge. 
Kennan, George Frost. 1985. O declinio da ordem europeia de Bismarck. Brasília: Editora Universidade de Brasília.

Kitchen, Martin. 2013. História da Alemanha Moderna: de 1800 aos dias de hoje. São Paulo: Cultrix.

Kuhne, Thomas. 2010. "Political Culture and Democratization." In Imperial Germany: 1871-1918, edited by James Retallack, 174-95. Oxford, UK: Oxford University Press.

Lerman, Katherine Anne. 2010. "Bismarckian Germany". In Imperial Germany: 1871-1918, edited by James Retallack, 18-39. Oxford: Oxford University Press, 2010.

Lobell, Steven. 2009. "Threat Assessment, the State, and Foreign Policy: a neoclassical realist model." In Neoclassical Realism, the State, and Foreign Policy, edited by Steven E. Lobell, Norrin M. Ripsman, and Jeffrey Taliaferro, 42-74. Cambridge: Cambridge University Press.

Mulligan, William. 2010. The Origins of the First World War. New York: Cambridge University Press.

Paul Harris, J. 2008. "Great Britain.” In The Origins of World War I, edited by Richard F. Hamilton, and Holger H Herwig, 266-99. New York: Cambridge University Press.

Rathbun, Brian. 2008. "A rose by any other name: Neoclassical realism as the logical and necessary extension of structural realism". Security Studies 17, no. 2: 294-321.

Rose, Gideon. 1998. "Neoclassical realism and theories of foreign policy". World politics 51, no. 1: 144-172.

Russel, Odo. 1873. Carta de Odo Russel, embaixador britânico para a Alemanha, ao seu superior, Lorde Granville, Secretário de Relações Exteriores da Grã-Bretanha. Carta. http://germanhistorydocs.ghi-dc.org/docpage.cfm?docpage_id=2829.

Schweller, Randall. 2008. "Neoclassical realism and state mobilization: expansionist ideology in the age of mass politics". In Neoclassical Realism, the State, and Foreign Policy, edited by Steven E. Lobell, Norrin M. Ripsman, and Jeffrey Taliaferro, 227-50. Cambridge: Cambridge University Press.

Taliaferro, Jeffrey W. 2001. "Security seeking under anarchy: Defensive realism revisited". International security 25, no. 3: 128-61. 
2009. "Neoclassical realism and resource extraction". In Neoclassical $\overline{R e a l i s m}$, the State, and Foreign Policy, edited by Steven E. Lobell, Norrin M. Ripsman, and Jeffrey Taliaferro, 42-74. Cambridge: Cambridge University Press.

Taliaferro, Jeffrey W., Steven Lobell, and Norrin Ripsman. 2009. "Introduction: neoclassical realism, the state, and foreign policy". In Neoclassical Realism, the State, and Foreign Policy, edited by Steven E. Lobell, Norrin M. Ripsman, and Jeffrey Taliaferro, 1-41. Cambridge: Cambridge University Press.

Waltz, Kenneth. 1979. Theory of International Politics. Long Grove: Waveland Press.

Williamson Jr., Samuel R., and Russel Van Wyk. 2003. July 1914: soldiers, statesmen, and the coming of the Great War: a brief documentary history. Boston: Bedford/ St. Martins.

Zakaria, Fareed. 1998. From Wealth to Power: the Unusual Origins of America's World Role. Princeton University Press. 


\section{NOTAS}

1. Texto original: "These authors seek to explain the grand strategy of a particular modern great power at a specific time or place and not recurrent patterns of international political outcomes".

2. Texto original: "the scope and the ambition of a country's foreign policy is driven first and foremost by its place in the international system and specifically by its relative material power capabilities".

3. Texto original: "States need to be able to reallocate societal resources otherwise spent on consumption to security and war-making functions. Variation on this dimension reflects institutional differences amongst countries".

4. Texto original: "...the state is an intervening variable between the international system and foreign policy”.

5. Texto original: "[...] an overall political situation in which all the great powers except France have need of us and are as far as possible kept from forming coalitions against us".

6. Texto original: "This war represents the German revolution, a greater political event than the French revolution of last century. [...] Not a single principle in the management of our foreign affairs, accepted by all statesmen for guidance up to six months ago, any longer exists. There is not a diplomatic tradition which has not been swept away. You have a new world, new influences at work, new and unknown objects and dangers with which to cope, at present involved in that obscurity incident to novelty in such affairs. We used to have discussions in this House about the balance of power. Lord Palmerston, eminently a practical man, trimmed the ship of State and shaped its policy with a view to preserve an equilibrium in Europe. [...] But what has really come to pass? The balance of power has been entirely destroyed, and the country which suffers most, and feels the effects of this great change most, is England".

7. Texto original: "When I say that it is our duty to endeavor to be ready at all times and for all emergencies, I imply that we must make greater exertions than other people for the same purpose, because of our geographical position. We are situated in the heart of Europe, and have at least three fronts open to an attack".

8. "Bismarck não possuía nenhum interesse direto nos Bálcãs e tinha muito medo de ser arrastado para o conflito. Já em 1876, o czar havia lhe perguntado de que lado ele ficaria na eventualidade de uma guerra entre a Rússia e a Áustria-Hungria por causa dos Bálcãs, mas ele se recusara a se comprometer. Insistiu em afirmar que a preservação da integridade do Império Habsburgo tinha importância fundamental para a Alemanha e fez tudo o que foi possível para evitar uma guerra nos Bálcãs” (Kitchen 2013, 218 ).

9. Texto original: "He had had trouble \& vexation enough to combat the Emperors desire to annex the German Provinces of Austria, the population of which certainly 
desired to form part of the great German Family, but that desire he would oppose so long as he was in power, because he preferred the Alliance and friendship of Austria to the annexation of Provinces that would add nothing to the strength and security of Germany and the loss of which would lessen the value of Austria as an ally.

The Swiss, for instance, were a German speaking nation, but Switzerland was of greater value as an independent friendly neighbor to Germany than as a province of the German Empire".

10. É verdade que a França recuperar-se-ia rápida e impressionantemente do impacto econômico provocado pela guerra Franco-Prussiana, mas ainda levaria algum tempo até restabelecer seu poder relativo anterior à guerra.

11. “'Embora o Reich Alemão seja muito poderoso', comentou o jornal russo Russki Mior, 'sem a permissão da Rússia, nem ele e nem qualquer outro Estado fará uso de seu poder em qualquer questão relevante. A última palavra permanece com o Czar russo”". (Mulligan 2010, 26).

12. (1) Como no caso da reivindicação da nacionalidade polonesa, minoria em ambas as potências e (2) a exemplo da neutralidade russa quando do processo de unificação alemã.

13. Texto original: "They served the security of the Reich and the preservation of peace in Europe, two virtually indistinguishable goals in Bismarck's mind. Alliances never became an end in themselves in Bismarck's foreign policy".

14. Texto original: "[ ...] hoped that the political parties he deemed to be 'friends of the empire' would form a steadfast 'national' coalition".

15. Texto original: " $[\ldots]$ did make him dependent on the monarch, who could dismiss him at will. But in actuality the relationship between Wilhelm I and his chancellor had slowly become reversed. Unlike his son and his grandson, this Kaiser was not particularly interested in ruling personally; therefore in most cases he was only too happy to follow Bismarck's advice and lead. Thus, the Reich chancellor's office became the most important power centre in Berlin. Until 1890 it was directed by Bismarck, who did not shy away from using modern means of charismatic leadership and propaganda".

16. Ao lado da Alemanha, outras potências começaram a dar seus primeiros passos rumo a uma política imperialista por volta deste período, especialmente Estados Unidos e Japão, mas também Itália e Bélgica, dentre outros.

17. Texto original: "No great decision may now be made without the German Empire and the German Emperor... The Crown sends its rays through 'Grace of God' into palaces as well as huts and - pardon me, if I dare say soEurope and the world listen intently in order to hear 'what says and thinks the German Emperor?', and not, what is the will of his chancellor!... Forever, and ever will only be one true Emperor in the world, and that is the German 
Kaiser, without regard for his person or his traits, alone by right of thousand-year tradition and his chancellor has to obey!"

18. Texto original: "For most contemporaries, the legitimacy of the German Empire was already beyond question by 1890".

19. Texto original: "Your Excellency is aware that I am firmly determined to dissolve the Reichstag in the event that it should reject the reinforcement ofour naval armaments which is so absolutely vital for our security and future. All other concerns and considerations must be subordinated to this question, which is a matter of importance for the Reich".

20. O caso da ferrovia Berlim-Bagdá é emblemático. Concebida no início da década de 1900, seus objetivos estavam vinculados à construção de uma nova via de transporte de passageiros, mas visavam principalmente facilitar o acesso alemão ao petróleo do Oriente Médio e às suas colônias africanas. Com apoio do kaiser, financiamento (especialmente do Deutsche Bank) e presença de engenheiros e demais trabalhadores alemães no projeto, a construção da ferrovia foi iniciada, embora tenha sido abortada pouco antes da eclosão da Primeira Guerra Mundial (Joll and Martell 2007; Mulligan 2010). Entretanto, um dos objetivos alemães foi obtido, já que a influência do Reich fez-se sentir mais tarde, quando o Império Otomano aliou-se à Alemanha na Primeira Guerra Mundial.

21. Texto original: "Tariffs and taxes increased during the Wilhelmine era in order to fund higher spending on the military, administration and social insurance".

22. Texto original: "Militarized culture of patriotism".

23. Texto original: "[ $[.$.$] was to cultivate in children a "powerful stimulus to$ emulate their fathers', the veterans of the war of 1870-71, who had 'risked everything to ensure the highest earthly blessings for their descendents."

24. Texto original: "[ [..] hygiene, physical education, reduction of the study burden and the need for a 'national foundation' to the curriculum. The objectives were clear: the army was to be provided with muscular young men". 


\section{RESUMO}

A Alemanha, após o seu processo de unificação, concluído em 1871, passou por um intenso crescimento e desenvolvimento até as vésperas da Primeira Guerra Mundial. Sempre orientados por uma percepção da distribuição de poder dentro do sistema internacional, seus líderes procuraram implementar uma política externa visando a ampliar o poder do país de forma a encontrar um melhor posicionamento relativo no sistema. Primeiramente, Bismarck buscou a manutenção do status quo pós-Guerra Franco-Prussiana, cujo resultado colocou a Alemanha em posição destacada na Europa. Já sob Guilherme II, uma política externa mais ambiciosa procurou promover internacionalmente o Império como uma potência de nível mundial. Condições internas e externas facilitaram e/ou dificultaram este processo. A elaboração de uma política de alianças, a intensificação da extração e da mobilização de recursos sociais, o estímulo a um nacionalismo de Estado, o combate a ideologias tidas como perigosas e o fortalecimento das estruturas e instituições do novo Império Alemão foram elementos extremamente importantes para transformar o que outrora era um emaranhado de Estados sem muita relevância política em uma potência mundial já em fins do século XIX.

Palavras-chave: Realismo Neoclássico; Império Alemão; Construção do Estado; Equilíbrio de Poder.

\section{ABSTRACT}

Germany, after its unification process, completed in 1871, underwent intense growth and development until the eve of the First World War. Always guided by a perception of the distribution of power within the international system, its leaders sought to implement a foreign policy aimed at expanding the country's power in order to find a better relative position in the system. Firstly, Otto von Bismarck looked for the maintenance of the post-Franco-Prussian War status quo, the result of which placed Germany in a prominent position in Europe. Under William II, a more ambitious foreign policy would promote the Empire internationally as a world power. Internal and external conditions facilitated and/or hindered this process. The development of a policy of alliances, the intensification of the extraction and mobilization of social resources, the encouragement of state nationalism, the fight against ideologies considered to be dangerous and the strengthening of the structures and institutions of the new German Empire, were extremely important elements to transform what was once a tangle of states without much political relevance into a world power already in the late 19th century.

Keywords: Neoclassical Realism; Imperial Germany; Construction of the State; Balance of Power.

Recebido em 15/06/2020. Aceito para publicação em 11/09/2020. 